\title{
Immediate loading implants with mandibular overdenture: a 48-month prospective follow-up study
}

\section{Karla ZANCOPE \\ Paulo Cézar SIMAMOTO JÚNIOR \\ Letícia Resende DAVI \\ Célio Jesus PRADO \\ Flávio Domingues das NEVES}

Department of Occlusion, Fixed Prostheses and Dental Materials, School of Dentistry, Universidade Federal de Uberlândia - UFU, Uberlândia, MG, Brazil.

Declaration of Interests: The authors certify that they have no commercial or associative interest that represents a conflict of interest in connection with the manuscript.

\section{Corresponding Author:}

Flávio Domingues das Neves

E-mail:neves@traing.com.br

DOI: 10.1590/1807-3107BOR-2014.vol28.0030 Epub XXXXX, 2014

Submitted: Oct 10,2013

Accepted for publication: May 06, 2014

Last revision: Jul 14,2014

\begin{abstract}
The aim of this prospective clinical study was to evaluate patient rehabilitation with two immediately loaded implants and bar-retained mandibular overdentures after 48 months of follow-up. Twenty patients were treated with two implants each; of these, 17 patients were re-evaluated for comparison. Gender, age, plaque index, gingival inflammation, keratinized mucosa, probing depth, bleeding, and implant loss data were recorded, and periapical radiographs were obtained for measurement of marginal bone loss. The results were statistically analyzed with one-way analysis of variance (ANOVA) followed by Student's t-test and Pearson's correlation test. To compare the data at baseline and after 48 months, a Wilcoxon Signed Rank Test was performed $(\alpha=0.05)$. One implant failed $(2.9 \%)$ during the first year and was replaced. A total of 35 implants were evaluated. Bone loss values were $0.52-2.89 \mathrm{~mm}$ (mean, 1.46 $\mathrm{mm}$ ). Probing depth was 1.75-3.75 mm (mean, $2.22 \mathrm{~mm}$ ). Correlations were found between bone loss and plaque index and between bone loss and gender, but bone loss did not correlate with gingival inflammation, keratinized mucosa, probing depth, or age. The overall survival rate of the implants was $97.1 \%$. Based on these results, the use of two immediately loaded splinted interforaminal implants to retain an overdenture with a bar attachment is a clinically viable option with a high survival rate.
\end{abstract}

Keywords: Denture, Complete; Dental Implants; Immediate Dental Implant Loading.

\section{Introduction}

The use of implants to rehabilitate edentulous patients is generally successful. ${ }^{1}$ With an overdenture, implants provide the main retention and stability for the removable prosthesis. Many studies have described the benefits of an overdenture as being low $\operatorname{cost}^{2}$ compared to a fixedimplant prosthesis over five implants for edentulous patients, ${ }^{3,4}$ having good stability and retention; ${ }^{5}$ using fewer implants to retain the prostheses; ${ }^{6}$ and providing improved masticatory function, ${ }^{7}$ improved quality of life, ${ }^{8}$ maximal bite force, ${ }^{3}$ good esthetics, ${ }^{6}$ and no compromise in periimplant soft tissue health or marginal bone levels. ${ }^{9}$

To simplify the implant treatment and shorten the dental rehabilitation time ${ }^{10}$ the implants can be installed in a one-stage procedure, which also has the advantage of lower cost. ${ }^{11}$ The immediate loading of implants shows high success rates in the mandible, irrespective of implant splint- 
ing and surface topography. ${ }^{12}$ Several researchers have reported marginal bone loss around immediately loaded implants, ${ }^{12,13}$ an important criterion for implant success after occlusal loading. The follow-up period also seems to be an important issue. A study ${ }^{14}$ with a follow-up period of less than 48 months concluded that the use of two splinted implants to retain a mandibular overdenture is a successful treatment option. However, this study did not evaluate immediately loaded implants. Mandibular overdentures supported by four one-piece, unsplinted, immediately loaded implants were reported in a previous study. ${ }^{10}$

Publications with short-term data suggest that overdentures require frequent maintenance, especially in the first year of use. ${ }^{13}$ However, with understanding of the mechanical and biological long-term behavior of these prostheses and implants with immediate loading, the dental professional can offer better planning, implementation, and technique control, providing considerable improvement of the cost/benefit ratio.

Thus, the aim of this prospective clinical study was to critically evaluate the outcomes, with a minimum of 48 months of follow-up, for edentulous patients who wore bimaxillary complete dentures and were rehabilitated with two immediately loaded implants and mandibular bar-retained overdentures. The null hypothesis of this study was that two immediately loaded implants and a mandibular barretained overdenture do not influence the survival rate of the implant and could be a clinically viable treatment option.

\section{Methodology Patient selection}

Participants were recruited from patients at the Dental School of the Universidade Federal de Uberlândia - UFU, Brazil. To calculate the sample size (n), the authors considered the expectation of the mean difference to be equal to 0.70 with an expected standard deviation of 0.80 ; the power of the study $(1-\beta)$ was set to 0.80 , and the probability of type I error ( $\alpha$ ) was set to $0.05 .{ }^{15} \mathrm{~A}$ minimum sample size of 13 patients $(n=13)$ was determined (SPSS 18.0 software, SPSS Inc., Chicago, USA).

Patient inclusion criteria were: total edentulism in the mandible for at least 6 months before implant placement; functional problems (e.g., discomfort and lack of stability); sufficient mandibular bone volume in the interforaminal area; bimaxillary complete dentures (both made from acrylic) for at least 12 months before the surgery; and adequate oral hygiene.

Twenty patients were included in this study (mean age of 62 years, range: 34 to 80 years). The prostheses were satisfactory with respect to base size, occlusal vertical dimension, occlusal contacts, and esthetics. However, these patients complained about the lack of retention and stability, poor masticatory function, ${ }^{7}$ lack of comfort, poor quality of life, ${ }^{8}$ and low selfesteem. Only one patient was a smoker, and none of the patients had diabetes or osteoporosis. Ethical approval was obtained from the Universidade Federal de Uberlândia Research Ethics Committee (\#260/11).

\section{Surgical and prosthodontic procedures}

Written informed consent was obtained from each patient. Panoramic radiographs were taken for the preoperative evaluation of each patient using a panoramic X-ray machine (Siemens Orthophos 3, Siemens ${ }^{\circledR}$, Munich, Germany) with an exposure time of 11.1 seconds and an average increase of $25 \%$ under a working current of $10 \mathrm{~mA}$ and a voltage of $68 \mathrm{kVp}$. Prophylactic antibiotics ( $2 \mathrm{~g}$ amoxicillin 2 hours before surgery) were administered to all patients, and a solution of $0.12 \%$ chlorhexidine digluconate (15 minutes before surgery and once a day after surgery) was used as a mouth rinse. A duplicate of the mandibular denture in acrylic resin was used as a surgical guide and to transfer the position of the installed implants (Master Screw, $3.75 \mathrm{~mm}$ diameter, Conexão Sistema de Próteses, São Paulo, Brazil), and for bite registration. Two external hexagon implants were inserted near the canine region of the mandible (interforaminal region) under local anesthesia. The implant length ranged from 10.0 to $15.0 \mathrm{~mm}$.

All patients received a bar/clip (Conexão Sistema de Próteses, São Paulo, Brazil) overdenture within a maximum period of 24 hours. The rounded plastic bar (Conexão Sistema de Próteses, São Paulo, Brazil) was cast with abutments (Conexão Sistema de Próteses, São Paulo, Brazil) to splint the implants, and the plastic clip (Conexão Sistema de Próteses, São Paulo, Brazil) was then connected to the mandibu- 
lar complete denture, converting it into an implantretained overdenture.

\section{Peri-implant evaluation}

The clinical parameters analyzed were:

- Plaque Index: Plaque adhering to the abutments was quantified using the Silness and Löe Plaque Index ${ }^{16}$ (PI) at four sites around the implant (mesial, distal, buccal, and lingual sites). The scale used was: $0=$ no plaque in the gingival area; $1=$ a film of plaque present; 2 = moderate visible plaque accumulation; and 3 = abundant plaque present.

- Gingival Index: The Gingival Index (GI) according to Silness and Lö $\mathrm{e}^{16}$ (with modifications) was used to evaluate each implant. ${ }^{17}$ The maximum degree of inflammation of the gingiva that surrounded the implant was assessed as follows: ${ }^{17}$ $0=$ no inflammation; $1=$ slight inflammation and slight changes in color and surface appearance; 2 = moderate inflammation, redness, and hyperplasia of the gingiva, accompanied by bleeding on pressure; and 3 = acute inflammation, highly red and hyperplastic gingiva, and a tendency to bleed spontaneously and ulcerate.

- Keratinized mucosa: The buccal side of the implant was assessed to quantify the extent of keratinized mucosa (Keratinized Mucosa Index [KMI]) around the implants. After the mucosa were lightly dried, the keratinized mucosa were measured using a periodontal probe with a millimeter index ${ }^{17}$ that rated the width on a scale of 0 to 3: $0=$ no keratinized mucosa; $1=1$ $\mathrm{mm}$ or less of keratinized mucosa; 2 = between 1 and $2 \mathrm{~mm}$ of keratinized mucosa; and $3=$ more than $2 \mathrm{~mm}$ of keratinized mucosa. ${ }^{16}$

- Pocket probing depths: The pocket probing depth (PPD) is defined as the linear distance from the free mucosal margin to the base of the pocket (apical termination of the junctional epithelium) and was measured (in millimeters) with a periodontal probe (Golgran Ind. e Com. de Instrumental Odontológico Ltda., São Caetano do Sul, Brazil). The PPD was calculated at four sites on each implant (mesial, distal, buccal, and lingual). ${ }^{18}$
- Bleeding on probing: A binomial (2-point) scale was used, namely, bleeding on probing, or no bleeding on probing. ${ }^{18}$

\section{Radiographic evaluation}

Intraoral periapical radiographs (Kodak, New York, USA) of the coronal parts of the implants were taken at time 0 (T0) (at occlusal loading), T1 (after 3 months), and T2 (after 48 months) using an X-ray unit (Endos AC, Villa Sistemi Medicali, Buccinasco, Italy) operating at $70 \mathrm{kVp}$ and $7 \mathrm{~mA}$. The exposure time was 0.6 seconds. The films were processed with an automatic Gendex machine (KaVo Dental GmbH, Biberach, Germany) in the normal mode, taking 5 minutes to complete the process. A modified plastic film holder was used (Cone Indicator, Indusbello, Londrina, Brazil). The radiographs were scanned (MD-300 Usb dental x-ray film scanner, Enteno, Beijing, China) and converted to digital files, and measurements of the marginal bone changes were made using free image analysis software (Image Tool, The University of Texas Health Science Center, San Antonio, USA). A single examiner made the measurements, which were calibrated using the implant length. Bone loss was measured on the radiographs as the distance between a point on the implant platform and the most cervical point at the marginal bone (Figure 1A and 1B).

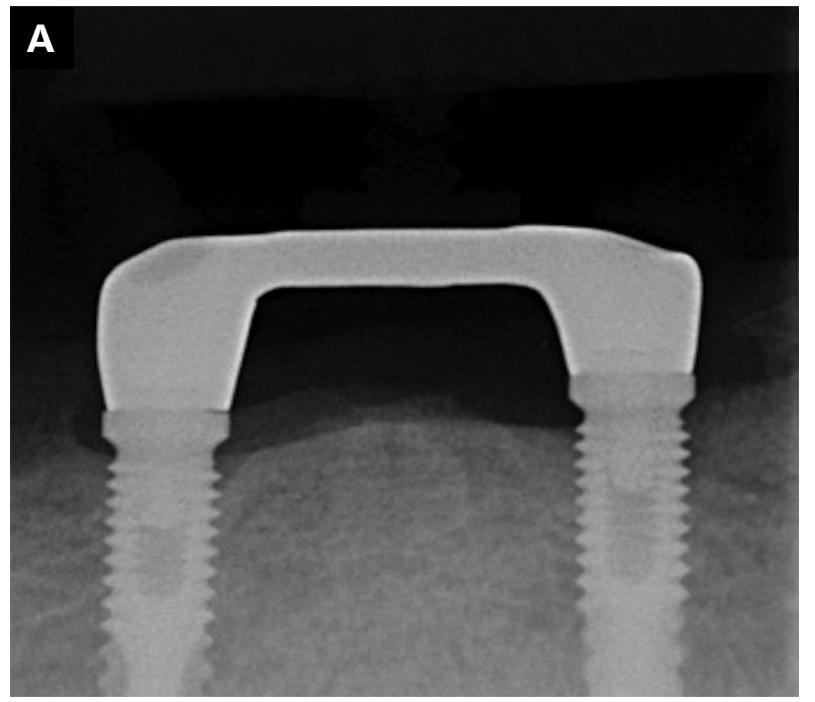

Figure 1A. A Radiographic view at baseline. 


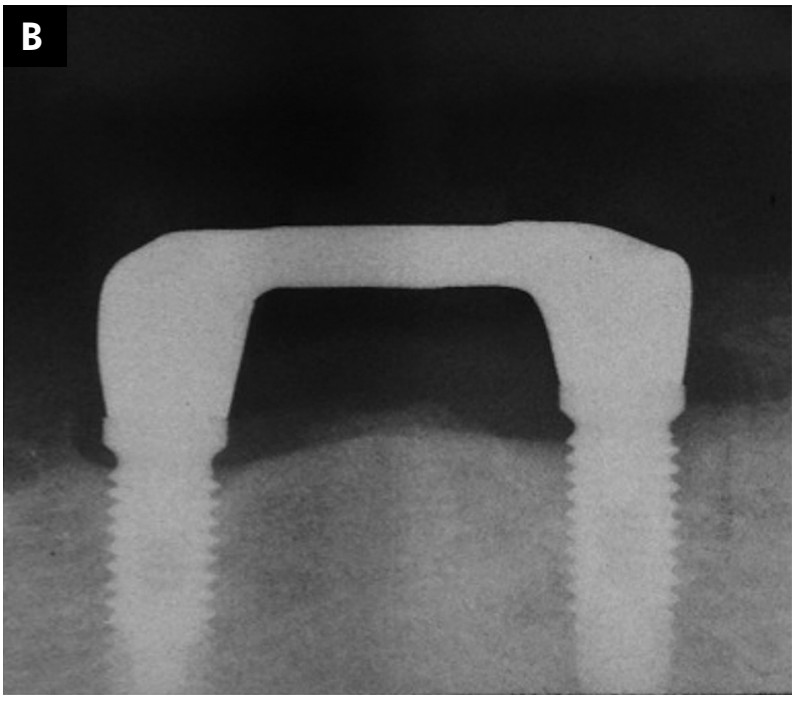

Figure 1B. Radiographic view at the 48-month follow-up.

\section{Data analysis}

The results were statistically analyzed with oneway analysis of variance (ANOVA) followed by Student's t-test and Pearson's correlation test. To compare the data at baseline and after 48 months, a Wilcoxon Signed Rank Test was performed. All analyses were performed using SPSS 18.0 software (SPSS Inc., Chicago, USA) at a confidence level of $95 \%$.

\section{Results}

\section{Implant failures and dropouts}

After 4 years, three patients were excluded from this study because of loss of contact. Seventeen patients received two implants each (a total of 35 implants); one implant failed (2.9\%) during the first year, and it was replaced. After 48 months of follow-up, the survival rate of the implants was $97.1 \%$. The 34 implants were functionally and clinically successful.

\section{Marginal bone loss and clinical analysis}

The mean marginal bone loss was $1.46 \mathrm{~mm}(0.52-$ $2.89 \mathrm{~mm})$. The mean probing depth was $2.22 \mathrm{~mm}(1.75$ to $3.75 \mathrm{~mm}$ ). Bleeding on probing was observed in four patients out of 16 (25\%). Tests were performed to evaluate the correlation between the mean bone loss and the clinical parameters. Correlations were found between bone loss and plaque index $(\mathrm{P}=0.020)$ and between bone loss and gender $(\mathrm{P}=0.019)$, but bone loss was not correlated with gingival inflammation $(\mathrm{P}=0.490)$, keratinized mucosa $(\mathrm{P}=0.394)$, probing depth $(P=0.732)$, or age $(P=0.272)$.

There was a statistically significant difference $(\mathrm{P}=<0.001)$ between the mean bone loss at baseline and after 48 months (median $=1.33 \mathrm{~mm}$ ).

\section{Prosthetic maintenance}

The main failure that occurred was fracturing of the overdenture around the clip. The failure rate was $18 \%$ (3 of 16 ).

\section{Discussion}

The null hypothesis of this study was accepted, which was that two immediately loaded implants and a mandibular bar-retained overdenture do not influence the implant survival rate. After the 48-month evaluation of the clinical and radiographic data, it was observed that an overdenture retained by immediately loaded implants does not affect the peri-implant tissues, allowing the application of this treatment in patients who cannot afford fixed-implant prostheses over four or five implants because the cost of this treatment is less than that of a fixed prosthesis. ${ }^{3,4}$

There are several options for treating a mandibular edentulous patient, all of which have high published survival rates, such as implant overdentures (immediate or delayed loading), implant fixed complete dental prostheses (immediate or delayed loading), and others. Randow et al..$^{19}$ compared immediate loading with the original delayed loading concept. During the 18-month observation period, no implant was lost in either of the two groups, and the authors concluded that the immediate-loading treatment had high implant survival rates.

The survival rate of immediate loading observed in this study was $97.1 \%$, confirming the values reported in the literature concerning conventional loading. 11,20,21,22,23 This success rate demonstrated a reliable index for immediate loading procedures. Splinting two interforaminal implants to support mandibular overdentures subjected to immediate loading significantly reduces the initial bone tissue strain. ${ }^{24}$ Prospective follow-ups observed the efficiency of two immediately loaded implants splinted by a bar. ${ }^{25}$ Another study found high survival rates of 
immediately loaded implants placed in the interforaminal area of the mandible and rigidly connected with a bar. ${ }^{26}$ However, that study used 4 implants per patient, unlike the present study. The failure rate of $2.9 \%$ (one implant) occurred during the first month of follow-up and was most likely due to masticatory overload that compromised the primary stability of the implant; this is the primary condition for immediate loading success. ${ }^{21}$

The average bone loss was $1.46 \mathrm{~mm}$ after 48 months of follow-up, which is supported by the results of similar studies that used immediate loading or conventional loading. ${ }^{1,5,27,28}$ Thus, rehabilitation does not require a waiting period before performing the second surgery, thereby increasing patient satisfaction and delivering the final prosthesis in a short period of time. ${ }^{29}$

Age did not correlate with bone loss; thus, an overdenture is indicated for healthy senescent patients as long as they do not present with local, systemic, or neurological contraindications for implant surgery. ${ }^{14}$ Patient gender was statistically correlated with bone loss. In this study, male patients showed greater bone loss than females. Bone loss in male patients may have occurred because of the higher measured plaque index values in these subjects. To avoid this problem, patients should return to the clinic for regular professional cleanings; this is particularly applicable to males, who are less receptive to the necessary care for maintaining the health of peri-implant tissues.

\section{References}

1. Cehreli MC, Karasoy D, Kökat AM, Akça K, Eckert S. A systematic review of marginal bone loss around implants retaining or supporting overdentures. Int J Oral Maxillofac Implants. 2010 Mar-Apr;25(2):266-77.

2. Naert IE, Hooghe M, Quirynen M, van Steenberghe D. The reliability of implant-retained hinging overdentures for the fully edentulous mandible. An up to 9-year longitudinal study. Clin Oral Investig. 1997 Sep;1(3):119-24.

3. Takanashi Y, Penrod JR, Chehade A, Klemetti E, Savard A, Lund JP, et al. Does a prosthodontist spend more time providing mandibular two-implant overdentures than conventional dentures?. Int J Prosthodont. 2002 Jul-Aug;15(4):397-403.

4. Thomason JM, Feine J, Exley C, Moynihan P, Muller F, Naert I, et al. Mandibular two implant-supported overdentures as the first choice standard of care for edentulous patients--the York Consensus Statement. Br Dent J. 2009 Aug 22;207(4):185-6.
With regard to prosthetic maintenance, the main failures (18\%) were related to fracture of the overdenture around the clip. According to a previous study, fractures of overdentures retained by implants tend to occur where there is a concentration of stress, usually over the implants..$^{30}$ Reinforcement of the denture base over the implants may increase resistance to this concentration of stress. ${ }^{30}$ In the present study, the authors placed a metal framework at the acrylic part over the implants to reinforce the prosthesis when necessary.

Although the length of the follow-up period (48 months) may be questionable compared to other implant studies, most researchers suggest that an overdenture prosthesis must be replaced when it is 5 years old. During this 48-month period, high survival rates of the implants were observed.

\section{Conclusion}

Based on the results of this study, the use of two immediately loaded splinted interforaminal implants and a bar attachment in overdenture patients is a clinically viable treatment option with a high survival rate.

\section{Acknowledgements}

The authors would like to acknowledge the support of Conexão Sistema de Próteses, São Paulo, Brazil for this work.

5. Goodacre CJ, Bernal G, Rungcharassaeng K, Kan JY. Clinical complications with implants and implant prostheses. J Prosthet Dent. 2003 Aug;90(2):121-32.

6. Quirynen M, Alsaadi G, Pauwels M, Haffajee A, van Steenberghe D, Naert I. Microbiological and clinical outcomes and patient satisfaction for two treatment options in the edentulous lower jaw after 10 years of function. Clin Oral Implants Res. 2005 Jun;16(3):277-87.

7. Borges TF, Mendes FA, Oliveira TRC, Prado CJ, Neves FD. Overdenture with immediate load: mastication and nutrition. Br J Nutr. 2011 Apr;105(7):990-4.

8. Borges TF, Mendes FA, Oliveira TR, Gomes VL, Prado CJ, Neves F. Mandibular overdentures with immediate loading: satisfaction and quality of life. Int J Prosthodont. 2011 Nov-Dec;24(6):534-9. 
9. Gadallah AA, Youssef HG, Shawky YM. A comparative study between early occlusal loading at 1 and 6 weeks in implant-retained mandibular overdentures. Implant Dent. 2012 Jun;21(3):242-7.

10. Mangano C, Mangano FG, Shibli JA, Ricci M, Perrotti V, d'Avila S, et al. Immediate loading of mandibular overdentures supported by unsplinted direct laser metal-forming implants: results from a 1-year prospective study. J Periodontol. 2012 Jan;83(1):70-8.

11. Turkyilmaz I. Clinical and radiological results of patients treated with two loading protocols for mandibular overdentures on Brånemark implants. J Clin Periodontol. 2006 Mar;33(3):233-8.

12. Attard NJ, Zarb GA. Immediate and early implant loading protocols: a literature review of clinical studies. J Prosthet Dent. 2005 Sep;94(3):242-58.

13. Cehreli MC, Uysal S, Akça K. Marginal bone level changes and prosthetic maintenance of mandibular overdentures supported by 2 implants: a 5-year randomized clinical trial. Clin Implant Dent Relat Res. 2010 Jun 1;12(2):114-21.

14. Meijer HJ, Batenburg RH, Raghoebar GM. Influence of patient age on the success rate of dental implants supporting an overdenture in an edentulous mandible: a 3-year prospective study. Int J Oral Maxillofac Implants. 2001 Jul-Aug;16(4):522-6.

15. Paolantonio M, Perinetti G, D'Ercole S, Graziani F, Catamo G, Sammartino $G$, et al. Internal decontamination of dental implants: an in vivo randomized microbiologic 6-month trial on the effects of a chlorhexidine gel. J Periodontol. 2008;79(8):1419-25.

16. Silness J, Löe H. Periodontal disease in pregnancy. II. correlation between oral hygiene and periodontal condition. Acta Odontol Scand. 1964 Feb;22(1):121-35.

17. Camargos GV, Prado CJ, Neves FD, Sartori IA. Clinical outcomes of single dental implants with external connections: results after 2 to 13 years. Int J Oral Maxillofac Implants. 2012 Jul-Aug;27(4):935-44.

18. Esposito M, Hirsch JM, Lekholm U, Thomsen P. Biological factors contributing to failures of osseointegrated oral implants. (I). Success criteria and epidemiology. Eur J Oral Sci. 1998 Jun;106(3):721-64.

19. Randow K, Ericsson I, Nilner K, Petersson A, Glantz PO. Immediate functional loading of Brånemark dental implants. An 18-month clinical follow-up study. Clin Oral Implants Res. 1999 Feb;10(1):8-15.
20. Misch CE, Perel ML, Wang HL, Sammartino G, GalindoMoreno P, Trisi P, et al. Implant success, survival, and failure: the International Congress of Oral Implantologists (ICOI) Pisa Consensus Conference. Implant Dent. 2008 Mar;17(1):5-15.

21. Nkenke E, Fenner M. Indications for immediate loading of implants and implant success. Clin Oral Implants Res. 2006 Oct;17 Suppl 2:19-34.

22. Stoumpis C, Kohal RJ. To splint or not to splint oral implants in the implant-supported overdenture therapy? A systematic literature review. J Oral Rehabil. 2011 Nov;38(11):857-69.

23. van Steenberghe D. A retrospective multicenter evaluation of the survival rate of osseointegrated fixtures supporting fixed partial prostheses in the treatment of partial edentulism. J Prosthet Dent. 1989 Feb;61(2):217-23.

24. Akça K, Akkocaoglu M, Cömert A, Tekdemir I, Cehreli MC. Bone strains around immediately loaded implants supporting mandibular overdentures in human cadavers. Int J Oral Maxillofac Implants. 2007 Jan-Feb;22(1):101-9.

25. Stricker A, Gutwald R, Schmelzeisen R, Gellrich NG. Immediate loading of 2 interforaminal dental implants supporting an overdenture: clinical and radiographic results after 24 months. Int J Oral Maxillofac Implants. 2004 NovDec;19(6):868-72.

26. Chiapasco M, Gatti C. Implant-retained mandibular overdentures with immediate loading: a 3- to 8-year prospective study on 328 implants. Clin Implant Dent Relat Res. 2003;5(1):29-38.

27. Geraets WG, Verheij HG, Wismeijer D, van der Stelt PF. Detecting bone loss along dental implants by subtraction of panoramic radiographs. Clin Oral Implants Res. 2012 Jul;23(7):861-5.

28. van Steenberghe D, Quirynen M, Naert I, Maffei G, Jacobs $\mathrm{R}$. Marginal bone loss around implants retaining hinging mandibular overdentures, at 4-, 8- and 12-years follow-up. J Clin Periodontol. 2001 Jul;28(7):628-33.

29. Pommer B, Zechner W, Watzak G, Ulm C, Watzek G, Tepper G. Progress and trends in patients' mindset on dental implants. II: implant acceptance, patient-perceived costs and patient satisfaction. Clin Oral Implants Res. 2011 Jan;22(1):106-12.

30. Gonda T, Maeda Y, Walton JN, MacEntee MI. Fracture incidence in mandibular overdentures retained by one or two implants. J Prosthet Dent. 2010 Mar;103(3):178-81. 